\title{
Characterization of Residual Stress as a Function of Friction Stir Welding Parameters in Oxide Dispersion Strengthened (ODS) Steel MA956
}

\author{
L.N. Brewer ${ }^{*+}$, M.S. Bennett, and B.W. Baker ${ }^{\#}$ \\ Naval Postgraduate School \\ E.A. Payzant and L.M. Sochalski-Kolbus \\ Oak Ridge National Laboratory
}

Friction stir welding (FSW)can generate large residual stresses during solid state joining of oxide dispersion strengthened steels.In this work, a plate of MA956 steel was friction stir welded at three conditions: $500 \mathrm{rpm} / 25$ millimeters per minute $(\mathrm{mmpm}), 400 \mathrm{rpm} / 50 \mathrm{mmpm}$ and 400 $\mathrm{rpm} / 100 \mathrm{mmpm}$. The residual stresses across these welds were measured using both x-ray and neutron diffraction techniques.The distribution and magnitude of the residual stresses agreed well between the two techniques. Longitudinal residual stresses up to eighty percent of the yield strength were observed for the $400 \mathrm{rpm} / 100 \mathrm{mmpm}$ condition. The surface residual stresses were somewhat larger on the root side of the weld than on the crown side.Increases in the relative heat input during FSW decreased the measured residual stresses in the stir zone and the thermomechanically affected zone (TMAZ). Increasing the traverse rate while holding the rotational speed fixed increased the residual stress levels. The fatigue strength of the material is predicted to decrease by at least twenty percent with cracking most likely in the TMAZ.

Key words: ODS steel, residual stress, friction stir welding, x-ray diffraction, neutron diffraction

\footnotetext{
* To whom all correspondence should be addressed: lnbrewer1@eng.ua.edu

${ }^{+}$L.N. Brewer is now an associate professor in the Metallurgical and Materials Engineering Department at the University of Alabama.
}

${ }^{\#}$ B. W. Baker is now an assistant professor in the Mechanical Engineering Department at the United States Naval Academy 


\section{Introduction.}

Despite the promise of oxide dispersion strengthened (ODS) steels and alloys for use in high temperature nuclear applications, joining these materials through traditional, fusion-based welding is highly problematic. The microstructural attributes that give these materials their strength can be severely degraded by fusion welding techniques. Processes like gas tungsten arc welding and gas metal arc welding result in transport and agglomeration of the finely dispersed oxides to the surface of the weld pool, as well as significant alterations to the grain sizes upon solidification. [1]The result isa significant reduction in yield strength across the weld and degraded creep properties in the large heat affected zone(HAZ) outside the weld pool. Other processes like electron beam welding and laser beam welding give similar results, coarsening and agglomerationof the oxide particles that give ODS steels their strength $[2,3]$.

Friction stir welding (FSW) shows significant promise as a solid-state joining technique for ODS steels. FSW involves the insertion of a hard, rotating tool into the surface of the pieces to be joined. The tool rotation heats the material to approximately eighty-to-ninety percent of the melting point of the alloy. $[4,5]$ The tool is then translated across the specimen, thus joining the material. This process does not melt the base metal, and preserves many of the mechanical and microstructural properties that make ODS steels attractive. Several authors have successfully demonstrated friction stir welding on ODS steels. [6-11] While defect-free welds can be achieved in ODS steels by FSW, some evolution in the stir zone (SZ) microstructure has been observed; including an increase in ferrite grain size, an increase in oxide particle size, and a resultant reduction in hardness and yield strength for the stir zone material. [6, 7, 11, 12]

Although FSW can significantly reduce the distortion that often accompanies fusion welding, the process can generate significant residual stresses.[13]For most alloys, longitudinal (parallel to the weld)residual stress profiles across the weld line display an ' $\mathrm{M}$ ' shape, with tensile maxima occurring in the thermomechanically affected zone (TMAZ) just beyond the tool shoulder. Moving from the TMAZ into the base metal, the tensile stresses rapidly decrease and are balanced by compressive stresses. In the stir zoneitself, the longitudinal stresses are reduced from the peak values at the TMAZ but are generally still tensile. This reduction in stress level may be caused by evolution of the microstructure, which results in a much lower yield strength in the SZ of the weld.[12, 14]In FSW of AA5083, Peel [15]showed that longitudinal residual 
stresses can reach up to $40 \%$ of the yield strength in the SZ, where FSW reduced the $0.2 \%$ offset yield strength in the SZ from $392 \mathrm{MPa}$ in the base metal to $147 \mathrm{MPa}$ at the weld center line. FSW modeling by Chen [16] and Bastier [17]predicted that the maximum longitudinal residual stresses are 40-50\% of yield strength in AA7050 and 6061-T6 respectively. Experimental work performed by Steuwer et al. [18]on HSLA-65 steel demonstrated a peak longitudinal residual stress over $80 \%$ of the nominal yield strength. Reynolds [14] observed a similar phenomenon in austenitic SS304 where the maximum longitudinal residual stress was $80 \%$ of yield for some conditions. In the ferritic stainless steel, 409M, Lakshminarayanan and Balasubramanian also observed tensile longitudinal residual stresses in the stir zone that were about $33 \%$ of the base plate material yield strength, but only $20 \%$ of the stir zone material yield strength. [19]In the ODS steel PM2000, Mathon [9]performed a neutron diffraction-based, residual stress analysis for a single (600 RPM, $50 \mathrm{mmpm}) \mathrm{FSW}$ condition and found that the longitudinal residual stresses on the advancing side of the weld can be as high as $50 \%$ of the yield strength of the base metal. This work also noted significant asymmetry in the residual stress distribution with larger stresses appearing on the advancing side of the weld. Residual stresses with these large magnitudes are significant as they can drastically reduce the fatigue life of friction stir welded components.

This paper examines the residual stress distributions generated from FSW of MA956 plate over several welding conditions. We will compare the surface residual stress values with the internal plate values by comparing x-ray and neutron diffraction data. Of importance is the interplay between the evolution of the microstructure during FSW and the distribution of residual stresses afterwards.

\section{Experimental Methods.}

The material used in these experiments consisted of two plates of MA956: a high-Cr, ferritic, oxide dispersion strengthened (ODS) alloy/steel produced by Special Metals Inc. Its chemical composition is listed in Table 1.

\begin{tabular}{|l|l|l|l|l|l|l|l|l|l|l|l|}
\hline $\mathrm{C}$ & $\mathrm{Cr}$ & $\mathrm{Al}$ & $\mathrm{Ti}$ & $\mathrm{Y}_{2} \mathrm{O}_{3}$ & $\mathrm{Mo}$ & $\mathrm{Mn}$ & $\mathrm{Ni}$ & $\mathrm{S}$ & $\mathrm{Si}$ & $\mathrm{P}$ & $\mathrm{Fe}$ \\
\hline 0.023 & 19.93 & 4.75 & 0.39 & 0.51 & 0.02 & 0.09 & 0.04 & 0.008 & 0.08 & 0.006 & Bal. \\
\hline
\end{tabular}

Table 1. Measured chemical composition of MA956 (all elements in weight percent). From 


\section{Baker, 2013 [6]}

The processing and FSW of these plates were accomplished as detailed in the work by Baker et al. [6] The alloy was canned and extruded at $1100^{\circ} \mathrm{C}$ and hot rolled three times at $1100^{\circ} \mathrm{C}$ over a period of 4 hours with reheating to $1100^{\circ} \mathrm{C}$ for 30 minutes before and after each rolling. The final plate was machined to a thickness of $4 \mathrm{~mm}$.

Friction stir welding was performed by MegaStir Technologies using a $25 \mathrm{~mm}$ diameter MS 80 grade polycrystalline cubic boron nitride (PCBN) tool with a convex scroll shoulder step spiral (CS4). The plunge force was a constant $17.8 \mathrm{kN}$. Three different conditions were selected to test the residual stress distribution across a range of heat inputs,from highest to lowest heat input: $500 \mathrm{rpm} / 25$ millimeters per minute $(\mathrm{mmpm}), 400 \mathrm{rpm} / 50 \mathrm{mmpm}, 400 \mathrm{rpm} / 100 \mathrm{mmpm}$. These FSW conditions correspond to rotational to traverse rate ratios of 20,8 , and 4 , respectively. As all of the other FSW parameters (FSW machine, tool geometry, plunge force, etc.) were held constant except for the welding rotation and traverse rates, it is assumed in this paper that the heat inputs during welding increased, in order, from 400/100 to $400 / 50$ to $500 / 25$. In each case, it is assumed that there is a relative increase in heat input although we did not measure the absolute value during the experiments. These welds were all performed in one pass, changing conditions mid-pass.

\section{X-RAY DIFFRACTION}

The x-ray residual stress measurements were performed with the iXRD Residual Stress Analyzer from Proto Manufacturing. The residual stress measurements were made using the traditional dspacing versus $\sin ^{2} \psi$ technique. [20]All residual stress measurements were performed with $\mathrm{Cr} k \alpha$ x-rays $(\lambda=2.291 \AA$ ), produced at an $\mathrm{x}$-ray tube power of $20 \mathrm{kV}$ and $4.0 \mathrm{~mA}$, under the conditions listed in Table 2. Alignment of the x-ray diffractometer was confirmed using a stress-free ferrite powder and a peened steel calibration sample (from Proto Manufacturing, $-502 \pm 35 \mathrm{MPa}$ ) prior to measuring residual stresses on the plate. Residual stress measurements were collected at $5 \mathrm{~mm}$ increments across the weld from the base metal (BM) to the TMAZ (Figure 1). To provide better spatial resolution, $1 \mathrm{~mm}$ increments were used across the TMAZ and theSZ. Figure 1 shows the

positions of the residual stress measurements, taken approximately at the midpoint of each welding condition to ensure steady state welding conditions were established. Line A 
corresponds to the $500 \mathrm{rpm} / 25 \mathrm{mmpm}$ condition, line $\mathrm{B}$ corresponds to the $400 \mathrm{rpm} / 50 \mathrm{mmpm}$ condition, and line $\mathrm{C}$ corresponds to the $400 \mathrm{rpm} / 100 \mathrm{mmpm}$ condition. Error bars for each $\mathrm{X}$-ray residual stress measurement were calculated based on an elliptical regression of the $d-\sin ^{2} \psi$ plot. These error bars had a median value of $4 \mathrm{MPa}$ with a maximum value of $13 \mathrm{MPa}$. In most cases, the error bars are the same size or slightly smaller than the data point symbols on the plots below.

\begin{tabular}{|c|c|}
\hline$\{\mathrm{hkl}\}$ reflection & ferrite $\{112\}$ \\
\hline Bragg angle for diffraction $(2 \theta)$ & $156.31^{\circ}$ \\
\hline Number of exposures per $\psi$ angle & 5 \\
\hline Time per exposure & 5 seconds \\
\hline Beam aperture diameter & $1 \mathrm{~mm}$ \\
\hline$\psi$ Angles & $\begin{array}{r} \pm 36.8^{\circ}, \pm 31.9^{\circ}, \pm 27.3^{\circ}, \pm 20.6^{\circ}, \\
\pm 13.2^{\circ}, \pm 13.2^{\circ}, \pm 11.8^{\circ}, \pm 10.5^{\circ}, \\
\pm 8.2^{\circ}, \pm 3.7^{\circ}, \pm 3.1^{\circ} \\
\hline \psi \text { oscillation }\end{array}$ \\
\hline
\end{tabular}

\section{Table 2. $\quad \mathbf{X}$-ray residual stress measurement conditions.}




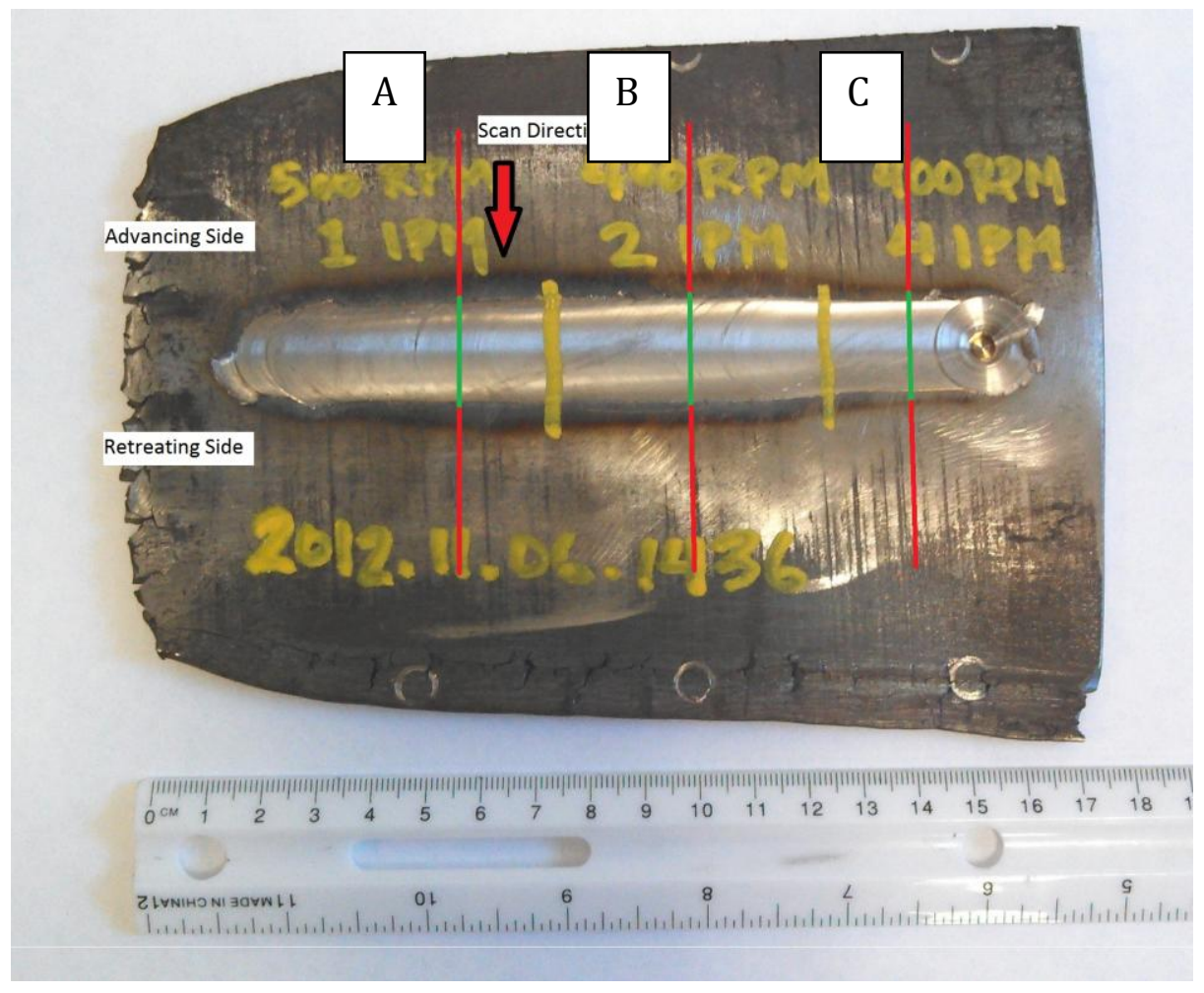

Figure 1. Geometry of $x$-ray residual stress measurements on friction stir welded plate. Note that the red line portions had spacing between analysis points of $5 \mathrm{~mm}$, while the green line portion had a spacing of $1 \mathrm{~mm}$.

Residual stress measurements were also collected as a function of depth. Electropolishing was utilized to remove material to depths of approximately $1 \mathrm{~mm}$ in two locations: $2 \mathrm{~mm}$ outside of the stir zone and along the weld centerline. Both of these measurements were made on the 400 $\mathrm{rpm} / 100 \mathrm{mmpm}$ section of the friction stir weld.Electropolishing was performed with Proto Manufacturing's 'Electrolyte A' at an applied voltage of $50 \mathrm{~V}$ with a resultant current of 2.2-3.0 A for approximately $160 \mathrm{~s}$ to reach each depth.The depth was measured using the auto-focusing pointer on the iXRD, accurate to approximately $0.01 \mathrm{~mm}$.

\section{NEUTRON DIFFRACTION:}

Neutron diffraction strain mapping [21] experiments were performed at the Neutron Residual Stress Facility (beam line HB-2B) at the High Flux Isotope Reactor (HFIR).[22]A double-focusing silicon monochromator was oriented to achieve a neutron wavelength of $\sim 1.733 \AA$, which locates the ODS ferritic steel $\{112\}$ reflection at $\sim 94^{\circ} 2 \theta$ (i.e., near $90^{\circ}$ to 
obtain a nearly cubic gauge volume). The incident beam was defined by a $1 \mathrm{~mm}$ wide x $5 \mathrm{~mm}$ high cadmium slit, and the diffracted beam slit was also $1 \mathrm{~mm}$ wide, located $20 \mathrm{~mm}$ from the sample, as illustrated in Figure 2. The $5 \mathrm{~mm}$ long dimension was oriented along the weld direction to increase the sample volume so that data could be collected quickly. For the longitudinal strain mapping direction, the incident beam height was restricted to $1 \mathrm{~mm}$, the smaller volume requiring proportionally longer counting times.

The sample was mounted to the sample stage in 2 different orientations (Figure 3). The sample was aligned in each orientation optically to a precision of $\pm 0.2 \mathrm{~mm}$, following which selected locations were verified to $\pm 0.1 \mathrm{~mm}$ using neutron "edge scans" to ensure that the gauge volume was fully buried in the sample at all measurement locations. This step was particularly necessary as the friction stir weldedplate was not perfectly flat, due both to rolling stresses in making the plates, and residual stresses from the FSW process. The weld line was not perfectly straight, and the width of the HAZ depended on the FSW parameters, so an estimate was made of the length of the region of interest and the collected data were later manually corrected so that the center of each weld line was defined to be at $\mathrm{x}=0$.

Data were collected for three orthogonal orientations (i.e., normal, longitudinal, and transverse with respect to the weld line), at selected points along lines at the center of each set of weld parameters (400/100, 400/50, and 500/25). The strain-free lattice parameter "d-zero" value was established by measuring the peak position at a location at a corner of the sample far from the weld line where the residual stress was deemed likely to be small. This is the "far-field reference" discussed in Hutchings.[21]The d-zero location was recorded as part of every neutron diffraction run in order to check that the instrument calibration remained constant as the sample was remounted to obtain the three strain directions at each point. The final data set showed a small shift in the d-zero position, and so a $2 \theta$ offset correction was applied to that set to bring the d-zero into agreement with the other data sets. The validity of the correction was supported by the resulting reasonable force balance of the data, as discussed in Hutchings.[21] 


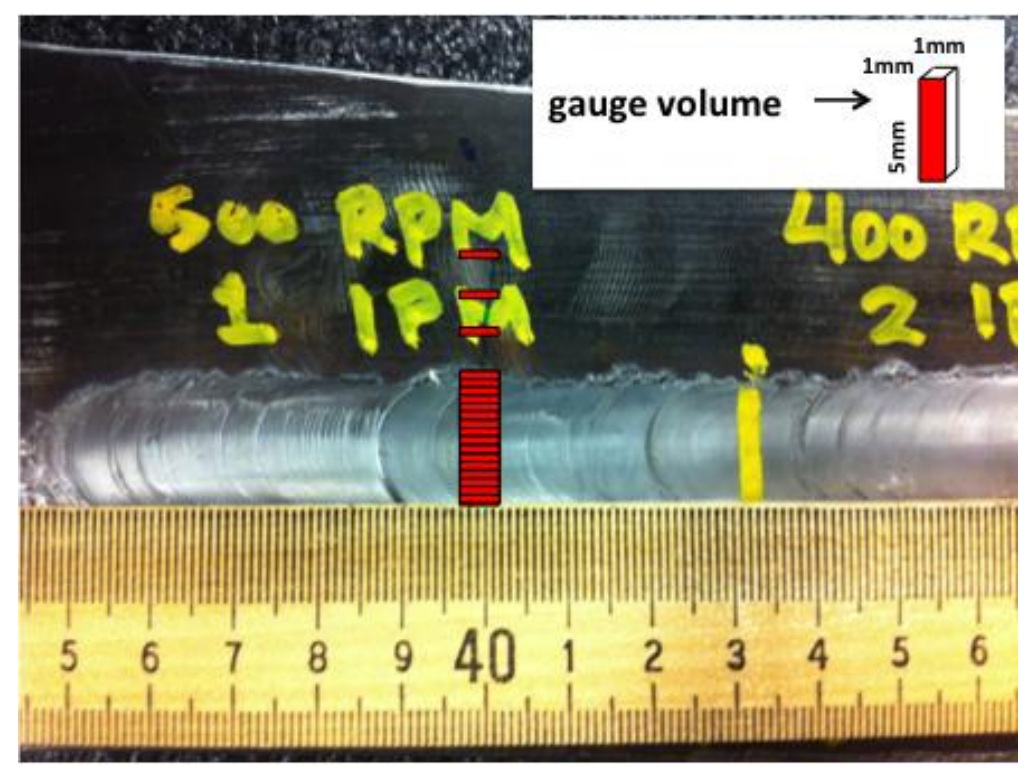

Figure 2. Geometry and placement of gauge volume for neutron diffraction measurements. Gauge volume was 1x5x1 mm for transverse and normal directions, but was 1x1x1 mm for longitudinal direction. Data was collected every $1 \mathrm{~mm}$ in weld region and every 4-5 mm outside of the weld.
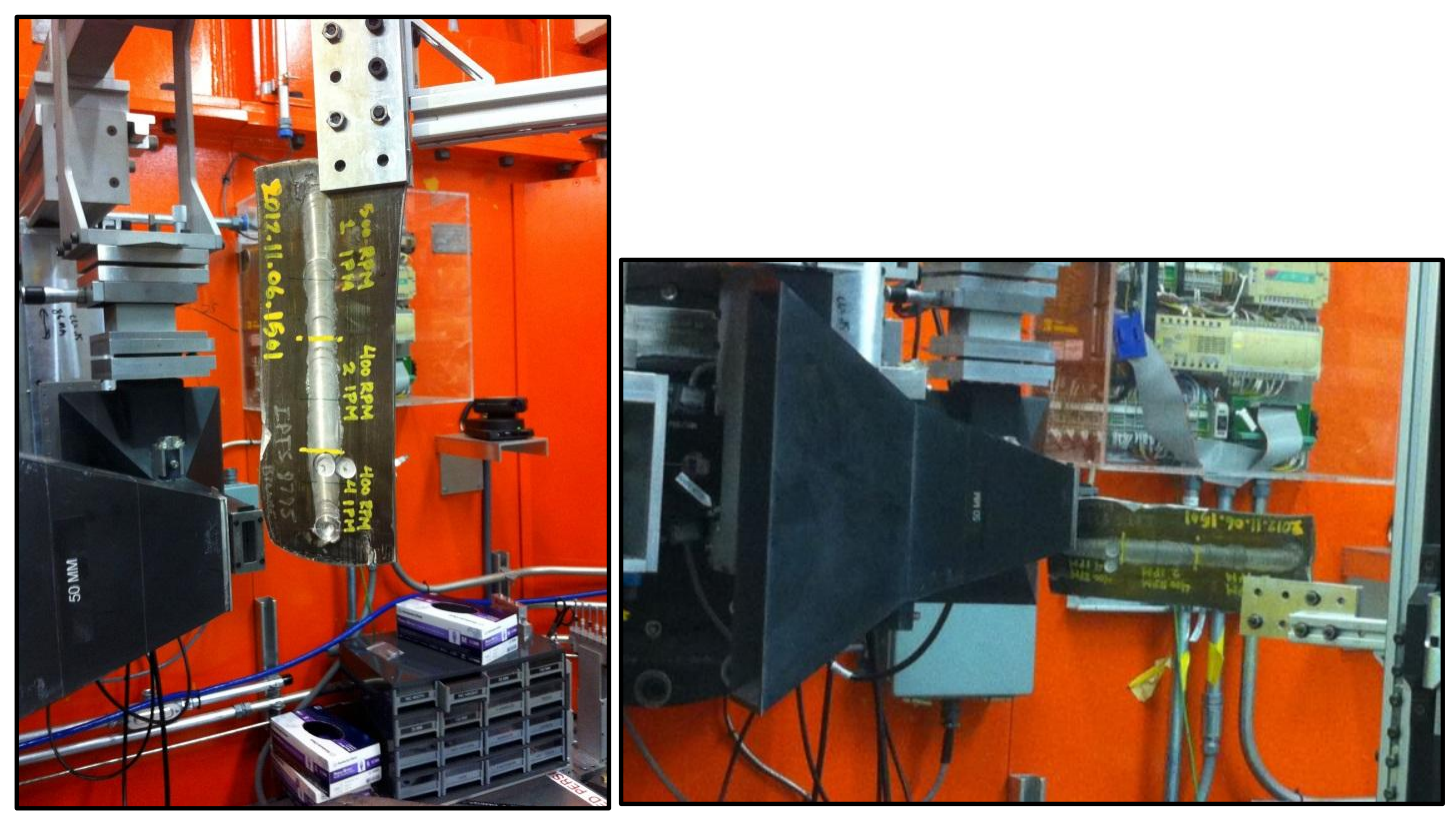

Figure 3. Geometry for neutron diffraction at HFIR HB2B beam line. (Left) geometry for transverse strain meausrement. The strains normal to the plate were measured by rotating the sample $90^{\circ}$ about the weld axis. (Right) geometry for longitudinal strain measurement 


\section{RESULTS}

\section{X-RAY DIFFRACTION RESIDUAL STRESS PROFILES:}

Each of the measured x-ray residual stress profiles on the crown side of the plate showed the "M" profile with varying degrees of intensity (Figure4). Peak longitudinal stresses occurred just beyond the weld nugget and tool shoulder, and were balanced by compressive stresses in theHAZ and BM. The profile was least pronounced for the highest heat input condition, 500/25, but as the heat input decreased, the "M" shape became more apparent. Residual stress peaks on the advancing and retreating sides werenearly equal in magnitude with the greatest difference being for the 400/50 condition. A more detailed view of the spatial gradient in longitudinal stress confirmed that the largest tensile stresses were generated by the lowest heat input (Figure 5).

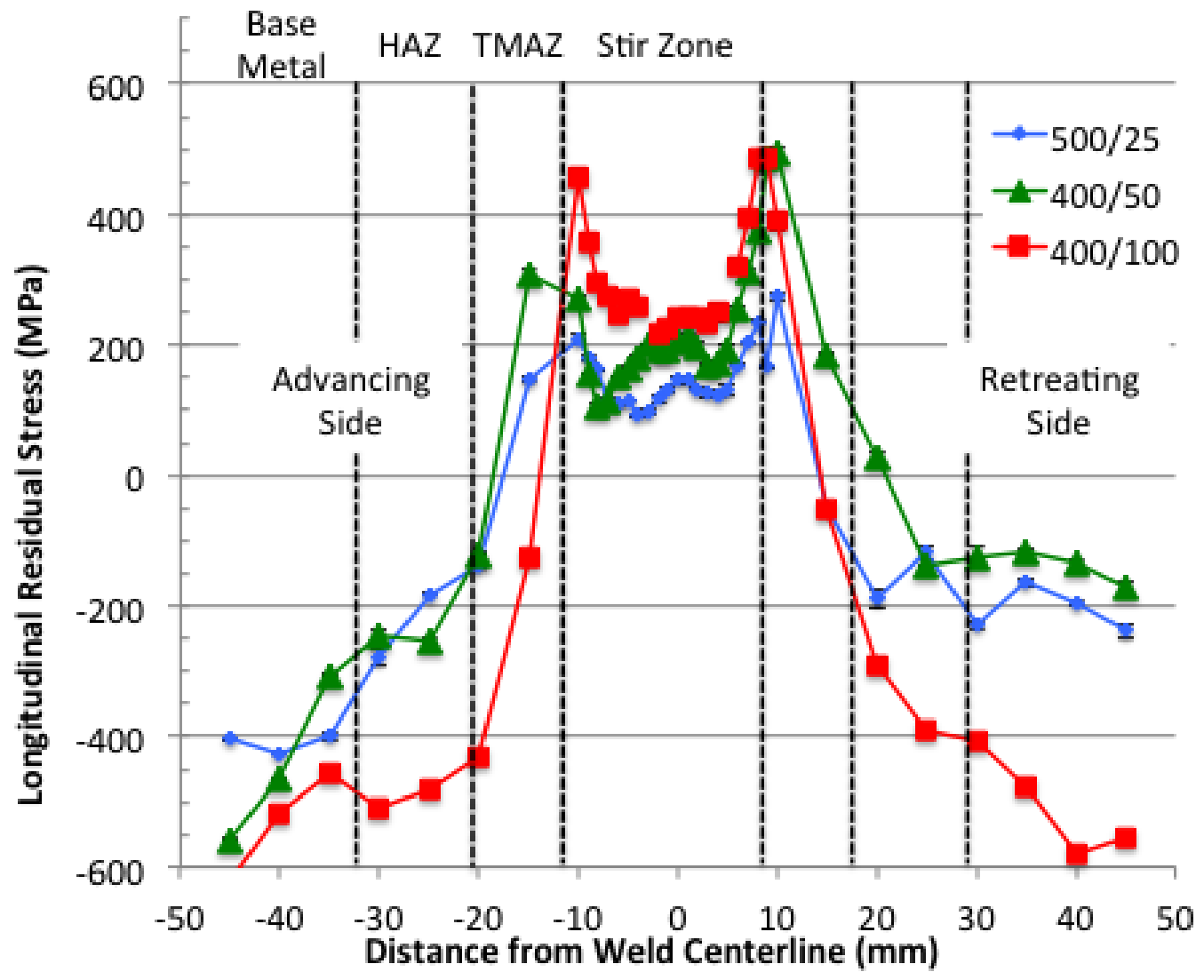

Figure 4. Longitudinal residual stresses measured by $x$-ray diffraction from the crown 
side of the plate. Note that the positions of the TMAZ and HAZ are only approximate.

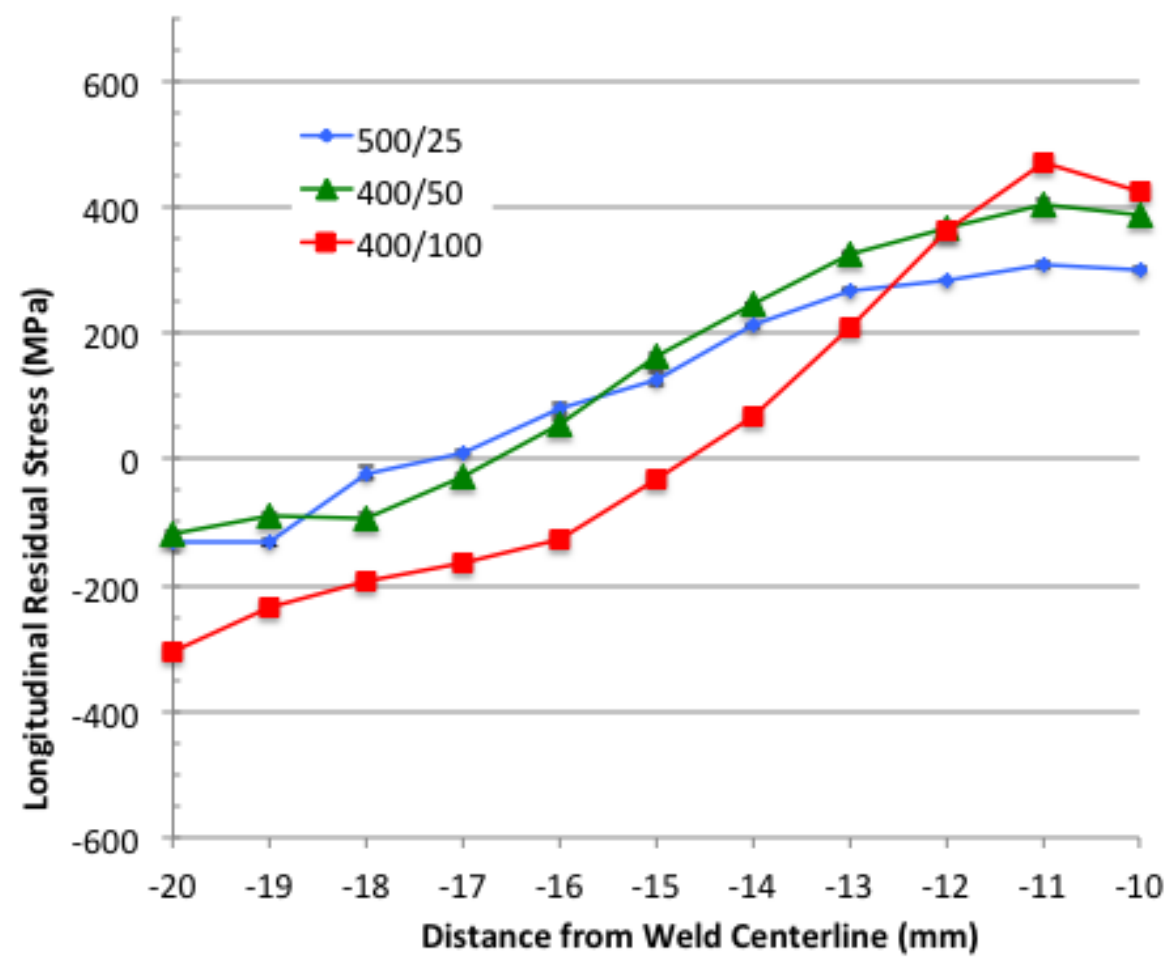

Figure 5. Longitudinal residual stresses (x-ray diffraction)near the TMAZon the crown side of the plate, on the advancing side of the friction stir weld (negative values for position always indicate advancing side of the weld nugget). Error bars are present on the plot but are approximately the size of the plot symbols.

Transverse stresses on the crown side of the plate also increased with lower heat input. In the SZ region, residual stress values ranged from -10 MPa (nearly zero) for the 500/25 condition to +233 MPa for the 400/100 condition (Figure 6). As expected, the transverse stresses were lower than the longitudinal stresses at the same point on each plate, but followed the same trends as longitudinal stresses with relative heat input. Interestingly, the transverse stresses evolved in more of a "W" pattern than the " $\mathrm{M}$ " pattern observed for the longitudinal stresses. More asymmetry in stress between the advancing and retreating sides of the weld was observed for the transverse stress distributions with larger residual stresses occurring on the advancing side of the weld. 


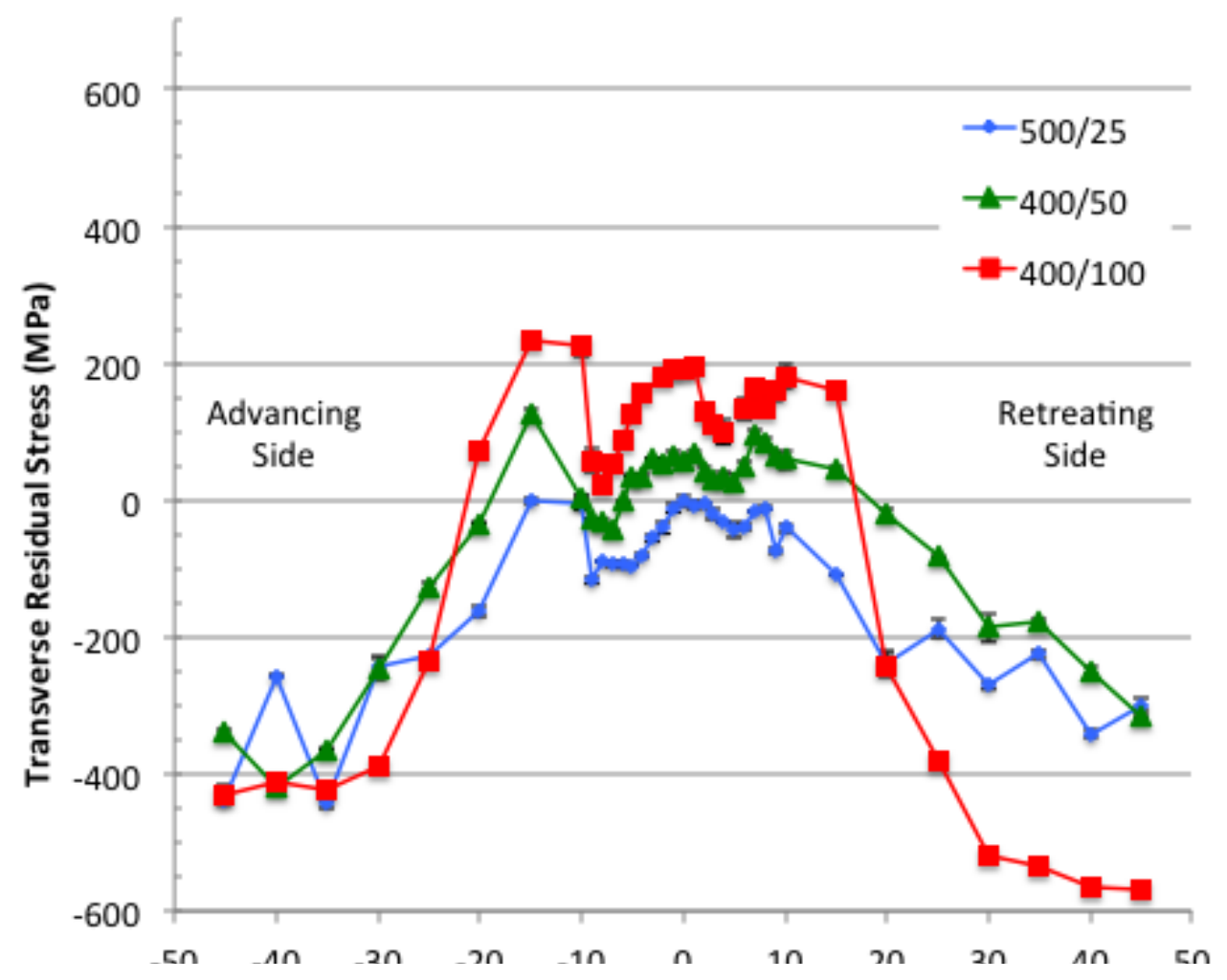

Figure 6. Transverse stresses (x-ray diffraction) from the crown side of the plate.

The residual stresses measured as a function of depth from the crown surface showed a consistent level of residual stress for the first several hundred microns below the surface (Figure7). At the weld centerline (SZ), the longitudinal stresses did not change significantly down to a depth of $1 \mathrm{~mm}$ below the surface. In contrast, the longitudinal stresses near the TMAZ decreased significantly with depth. From $+900 \mathrm{MPa}$ at the surface, the longitudinal stress peak decreased to less than $+600 \mathrm{MPa}$. This abrupt change is likely due to the abrupt change in microstructure. As see in Figure 7, the shape of the weld nugget is at an angle to the plate surface. As one takes measurements with depth, the measurement volume will likely pass through a gradient in microstructure and therefore a corresponding change inresidual stress level. 


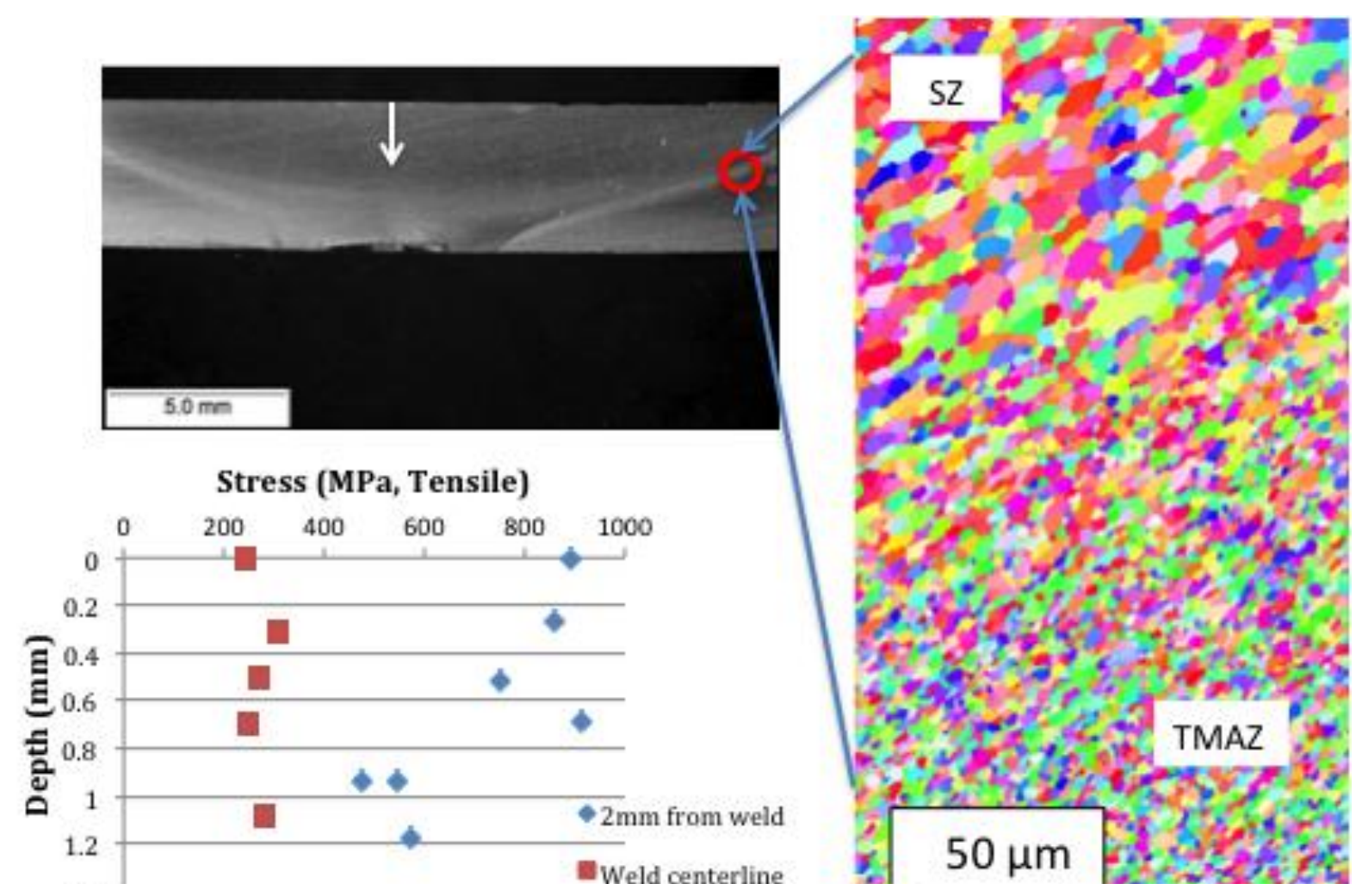

Figure 7. Longitudinal stresses (x-ray diffraction)measured as a function of depth for the 400/100 condition. The optical macrograph (top) shows a cross section of the friction stir weld. The white arrow indicates the approximate location of the depth profile in the center of the SZ (red squares). The data from the TMAZ (blue diamonds) was taken just off the right hand side of this macrograph. The image to the right is an inverse pole figure map of the boundary between the SZ and the TMAZ for this weld, showing the abrupt change in grain size at this boundary. This orientation map is taken from Baker et al. 2014[23]

Measurements taken across the root side of the weld revealed distinct differences from those taken across the crown of the plate (Figure8). The root-side profiles displayed the characteristic "M" shape, and again decreasing relative heat input resulted in larger residual stresses. However, more asymmetry was observed between stress peaks on the advancing and retreating sides. The 500/25 and 400/100 conditions hadpeak longitudinal stresses on the advancing side of $621 \mathrm{MPa}$ and $402 \mathrm{MPa}$; respectively, while the peak stresses on the retreating side were nearly $140 \mathrm{MPa}$ less for each case. Less asymmetry was observed for the 400/50 condition, where peaks on the advancing and retreating sides were only different by $70 \mathrm{MPa}$. Moreover, the magnitudes of the peak longitudinal residual stresses (those at the advancing side- 
TMAZ) on the root side of the plate were more than $100 \mathrm{MPa}$ larger than those on the crown side of the plate. Lastly, the difference in stress level between the peak at the TMAZ and the center of the SZ was qualitatively larger on the root side of the plate than on the crown side. It should be noted that the surface condition left by FSW at the center of the SZ on the root side of the weld did not allow for reliable measurement of the residual stresses for a width of approximately $6 \mathrm{~mm}$. These points have been intentionally omitted from Figure 8 .

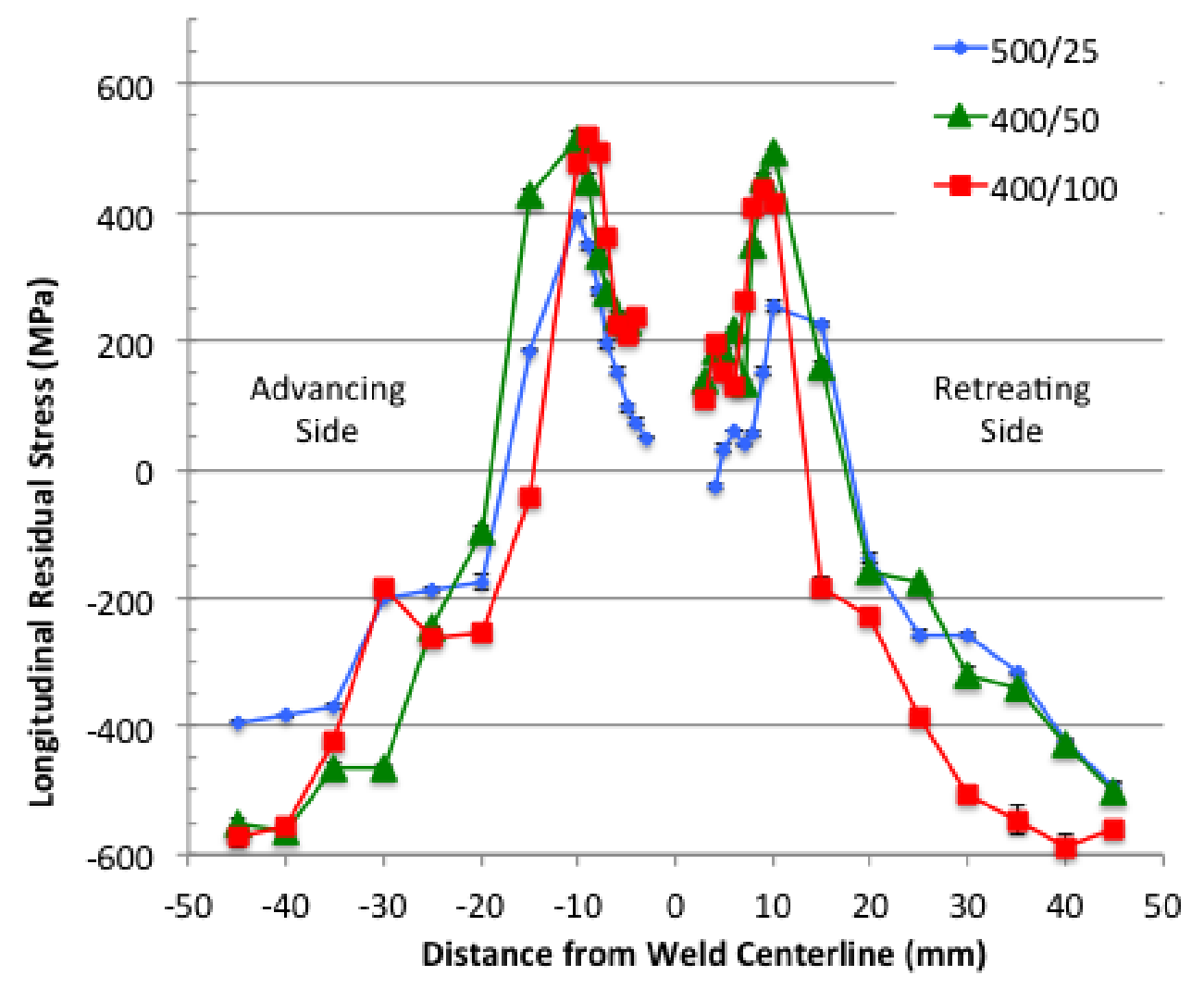

Figure 8. Longitudinal residual stress profiles (x-ray diffraction) from the root side of the plate. Note that several points right at the centerline have been removed due to unacceptable levels of surface roughness in these areas.

\section{NEUTRON DIFFRACTION RESIDUAL STRESS PROFILES:}

The neutron diffraction experiments produced similar residual stress profiles to those recorded by x-ray diffraction (Figure 9). The "M" shape profile was clearly observed for the longitudinal stresses, but not for the transverse or normal stresses. The level of longitudinal residual stress for the 400/100 condition was notably larger in the SZ than for the other two FSW 
conditions which were almost indistinguishable. The magnitude of the stresses agreed more closely with the larger stresses measured on the root side of the plate as measured by x-ray diffraction. The normal stressesoutside of the SZ were very close to zero, indicating a plane stress configuration for the plate; however, the normal stresses inside of the SZ were measurably tensile and uniform. Neutron diffraction-based residual stress profiles did not display much anisotropy between the peaks on the advancing versus retreating sides. The transverse residual stresses measured by neutron diffraction were primarily tensile and were relatively uniform across the weld region. The "W" profile for transverse stresses was not observed in the neutron diffraction results.

The calculated residual stress data in Fig 9 appears to have a slightly positive overall stress(by $\sim 50 \mathrm{MPa}$ ), particularly for the transverse stress data. This offset may be due to cumulative errors in the measurement, or invalid assumptions in the calculation of the stresses from the measured strains. It was assumed that the directions (normal, transverse, and longitudinal) represent the principal axes based on the sample geometry, but if this were not the case, then error would be introduced from not considering the effect of shear strains. This problem could be avoided by measuring the same locations in at least three more directions and solving for the full strain tensor.As additional neutron beam time was not available for these measurements, the principal directions were assumed to be known. It was also assumed that the elastic modulus (200 GPa) and Poisson ratio (0.29) were accurately known and were invariant in the base metal, the heat affected zone, and the stir zone. These assumptionscan affect the calculated residual stress, but not the measured residual elastic strains.

The peak breadth from neutron diffraction (full width at half maximum) clearly showed the effects of FSW (Figure 10). For each FSW condition, the peak breadth narrowed considerably in the SZ compared with the base metal or the TMAZ. The peak breadth in the SZ for all three FSW conditions possessed approximately the same value. Interestingly, the value on the advancing side of the SZ was slightly higher than on the retreating side of the SZ for all cases. In addition, the peak breadth in the advancing side TMAZ was larger for the 400/100 condition than the base metal or the other FSW conditions. The widths of the narrow peak regions did not vary meaningfully with heat input. In addition, the width of the narrow peak region was slightly smaller than for the other two FSW conditions, presumably because it generated less heat input. 

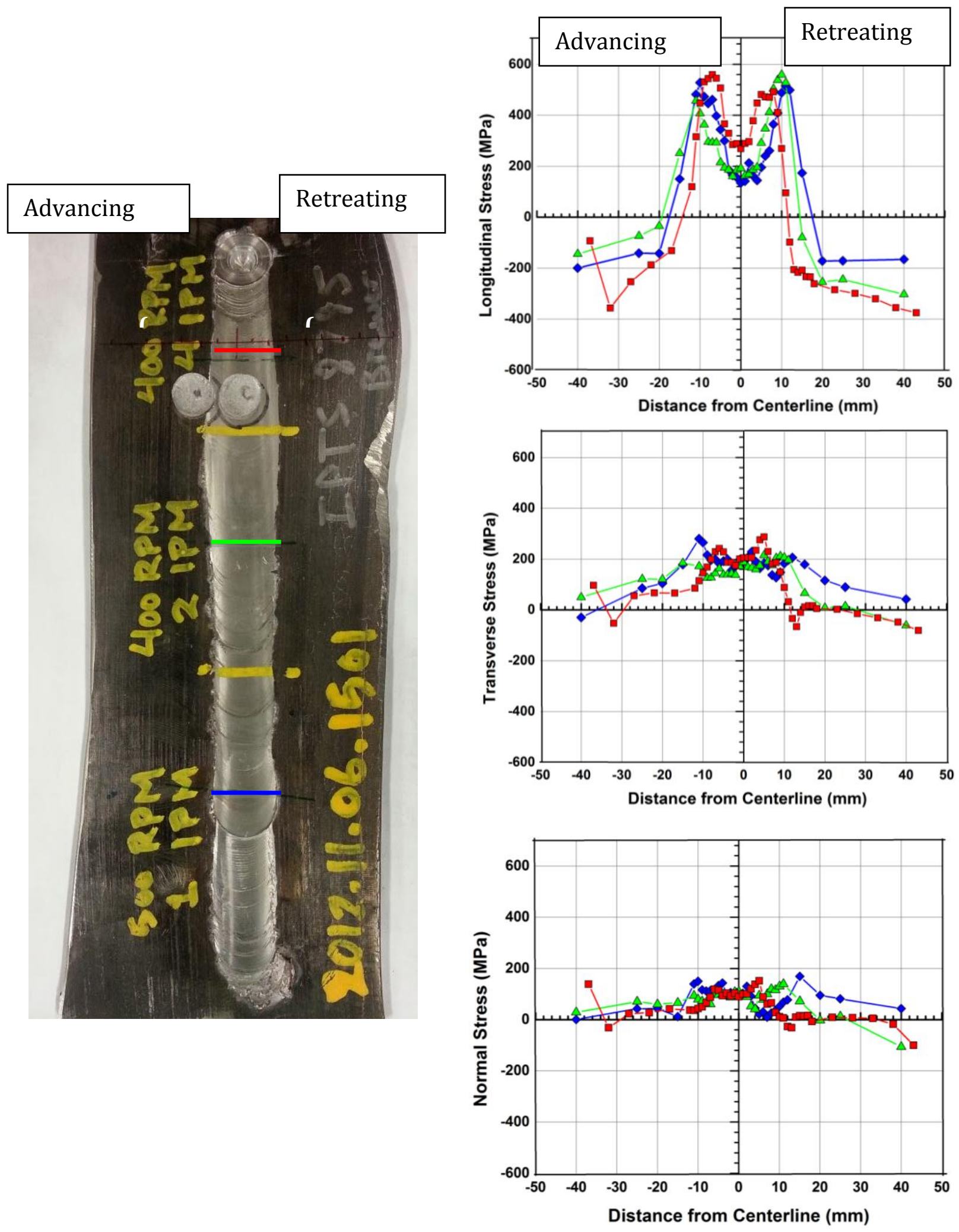

Figure 9. Residual stress profiles measured by neutron diffraction for each FSW condition. (A)Blue line and symbols represent 500/25 (B) Green line and symbols represent 400/50 (C) red line and symbols represent 400/100. 


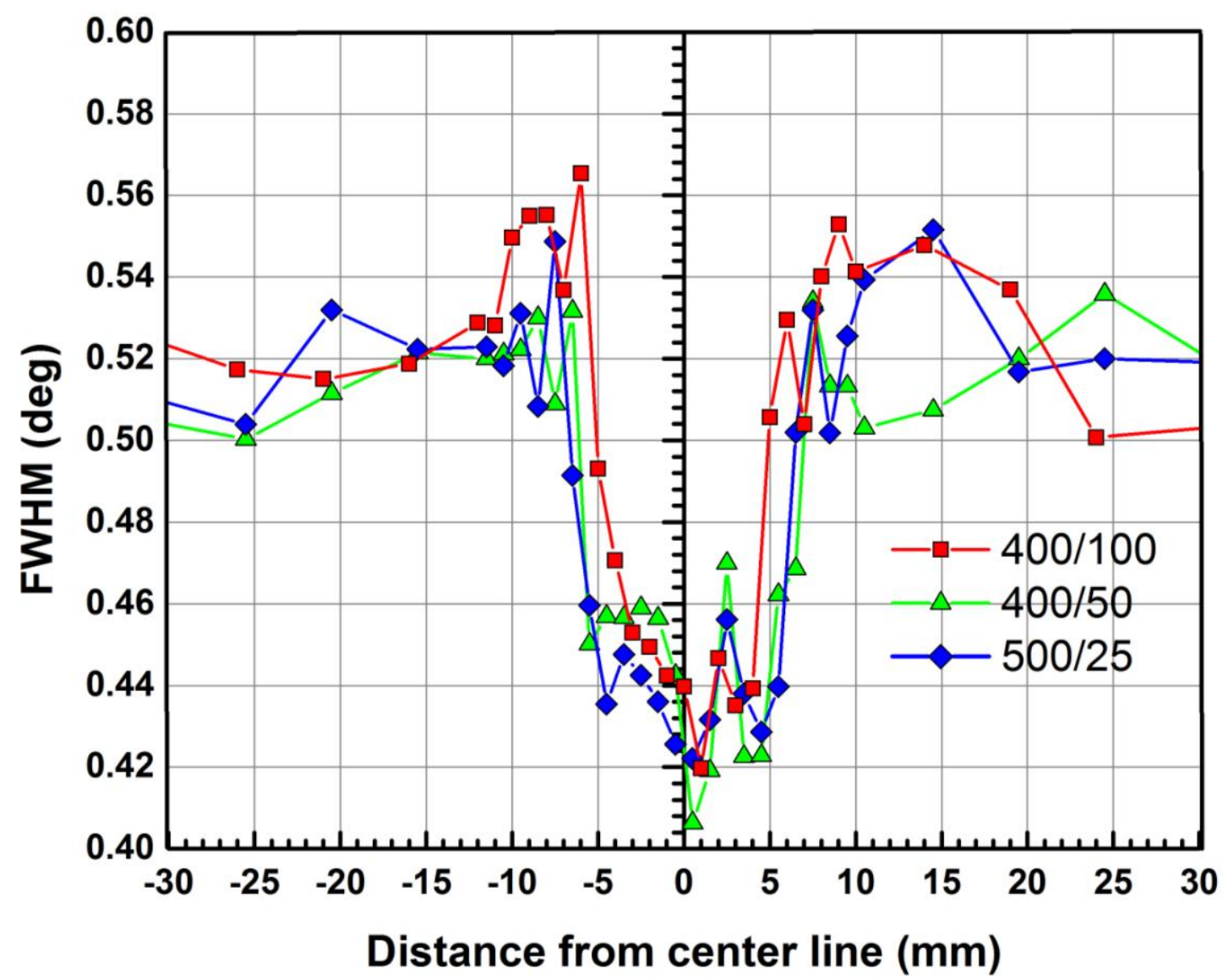

Figure 10. Spatial distribution of neutron diffraction peak full-width-at-halfmaximum (FWHM) across the three welds for the stress measurements in the transverse direction. The trend seen here is similar for the longitudinal and normal directions. An empirical estimated error gave 0.05 degrees based on the mean of the FWHM of each measurement point subtracted from that of the Fe $\{211\}$ standard powder measurement for $\mathrm{HB}-2 \mathrm{~B}$. 


\section{Discussion.}

The magnitude of the longitudinal and transverse residual stresses measured in these experiments increased with decreasing relative heat input. While the heat input during FSW was not directly measured, it should scale with the ratio of the rotational speed to the transverse speed (given a fixed plate material, tool type and geometry, and plunge force). $[12,24,25]$ These rotational to traverse speed ratios are 20,8 , and 4 for the 500/25, 400/50, and 400/100 conditions respectively. So we see from Figures 4, 5, 6, 8, and 9 that the magnitude of the residual stresses decreased as this ratio became larger. Furthermore, the residual stress levels increased between the 400/50 and 400/100 conditions as the traverse speed increased. This connection between residual stress level and traverse speed has been clearly described by Steuwer using synchrotron x-ray diffraction measurements on friction stir welded HSLA-65 steel.[18] The same trend was also observed in aluminum alloys, such as AA5083, in work by Peel et al. [15] One of the explanations in the literature for this trend is that a faster traverse rate provides less time at elevated temperature for the residual stresses to relax. [13] The surface residual stresses were notably different from the crown side versus the root side of the weld with root side stresses being larger. The neutron diffraction measurements, which were taken from the center of the plate, were closer in magnitude to the root side of the plate. The reason for this difference in unclear but may be due to the presence of an anvil on the root side which can act as a thermal sink thus reducing the amount of time at elevated temperature available for thermal relaxation as the weld material cools. It should be noted that this MA956 alloy should not experience any phase transformations over the temperature range during FSW.

The distribution and magnitude of residual stresses after FSW are closely connected to the change in microstructure in the material. In this study, the welds are all undermatched with respect to the base plate material. Baker has measured the microstructural attributes and the yield strength of the SZ material under the same FSW conditions used here (Table 3). [12, 23] The room temperature yield strength of this alloy has decreased by approximately $40 \%$ after FSW. This reduction in yield strength is caused primarily by the coarsening of the oxide particlesand the growth of ferrite grains 
in the SZ material. In addition, this material is recrystallized with a lower dislocation density after FSW. This decrease in dislocation density is the cause for the reduction in the diffraction peak breadth in the SZ (see Figure 10). With this reduction in yield strength, the SZ material cannot support residual stresses as large as the plate material, which is much stronger. It is important to account for this reduction in yield strength when considering the magnitude of the residual stresses. The longitudinal stress in the SZ for the 400/100 condition is approximately $240 \mathrm{MPa}$ (crown side). This stress is only $26 \%$ of the plate material yield strength, but it is $44 \%$ of the SZ material's yield strength. By plotting the ratio of the measured longitudinal residual stress to the measured yield strength of the plate material and the SZ, it can be seen that the 500/25 condition actually generates residual stresses that are a comparable fraction of its yield strength in the SZas in the 400/100 condition (Figure 11). As the yield strength for these two FSW conditions is quite similar (Table 3), it would seem that the large difference in residual stress magnitude is from the difference in cooling rate provided by the much faster traverse rate for the 400/100 condition than from a large difference in SZ yield strength.

\begin{tabular}{|c|c|c|c|c|c|c|}
\hline & & $\begin{array}{c}\text { Ferrite } \\
\text { Grain }\end{array}$ & $\begin{array}{c}\text { Average } \\
\text { Oxide } \\
\text { Particle } \\
\text { Size }\end{array}$ & $\sigma_{\text {YS }}$ & $\sigma_{\text {UTS }}$ & \\
Weld & Heat Index & $(\mu \mathrm{m})$ & $(\mathrm{nm})$ & $(\mathrm{MPa})$ & $(\mathrm{MPa})$ & Hardness \\
\hline Condition & - & 0.890 & 8.1 & 909 & 991 & $\left(\mathrm{H}_{\mathrm{V}}\right)$ \\
\hline $400-100$ & 4 & 6.94 & 166 & 539 & 696 & 346 \\
\hline $500-25$ & 20 & 12.5 & 343 & 530 & 698 & 225 \\
\hline
\end{tabular}

Table 3. Summary of microstructural attributes and mechanical properties for friction stir welded MA956. Note that the yield strengths for the friction stir welded conditions are from stir zone material. Table modified from Baker et al. 2014 [12] 


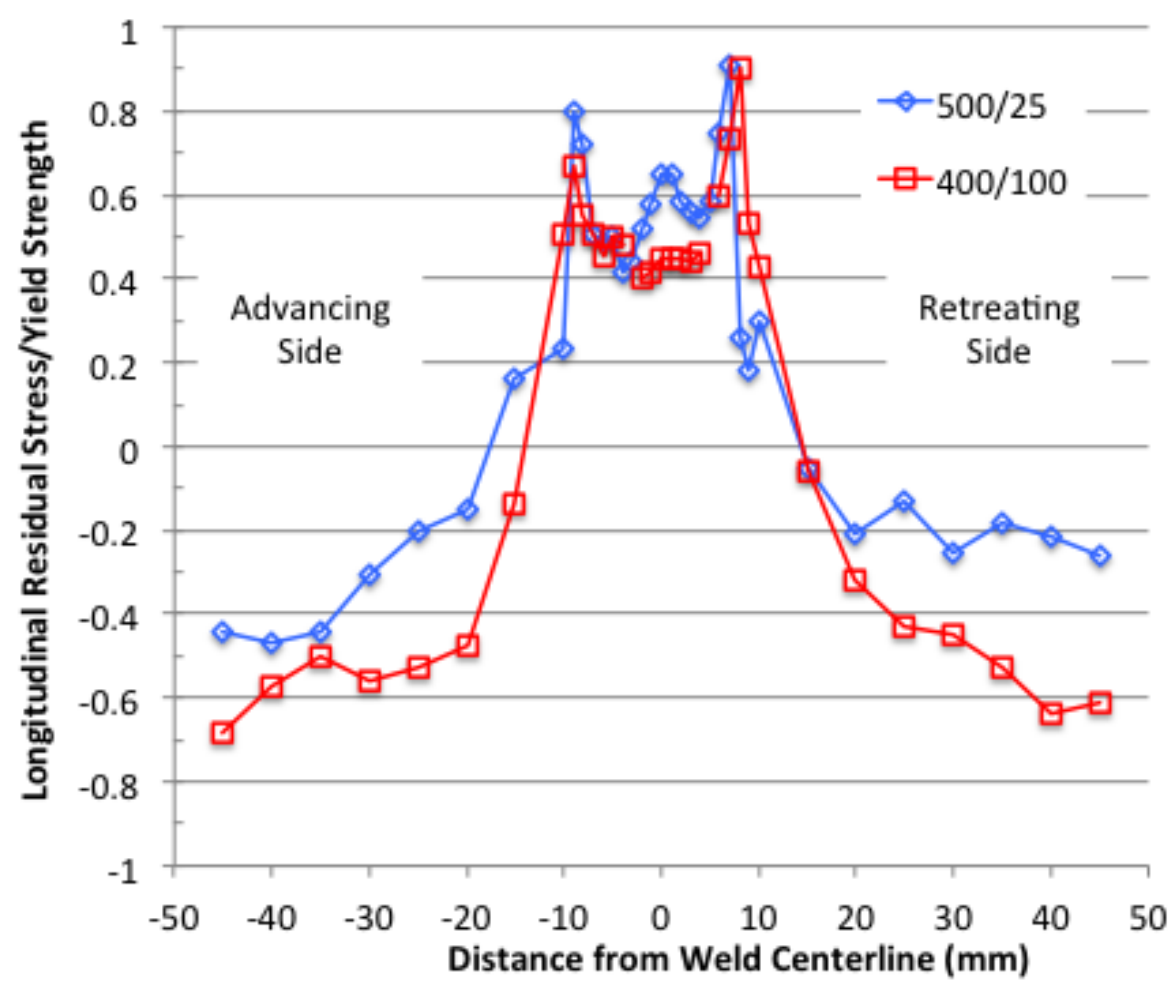

Figure 11. Distribution of longitudinal residual stresses normalized by yield strength for each weld microstructure. The stresses in the SZ are normalized by yield strengths measured from actual friction stir welded material in work by Baker et al.

The nature of the particular steel and its microstructure can strongly affect the distribution and magnitude of residual stresses after FSW. The magnitude of longitudinal residual stress measured in this study is similar to that reported by Mathon on PM2000, a very similar alloy to MA956. [9] Both studies show the "M" profile for longitudinal residual stresses; however, Mathon's results also show larger transverse stresses that also possess the "M" profile. The neutron diffraction data in this paper show a relatively flat transverse stress profile, which is lower in magnitude (Figure 9). Some care should be taken in a direct comparison between the two papers because the FSW conditions and geometry in Mathon's work (600 RPM, 50 MMPM, $1.3 \mathrm{~mm}$ thick plate, possibly different tool geometry) are substantially different than the present conditions. In contrast, the work of Barnes and Steuwer used very similar FSW conditions as those used 
in the current experiments, but on a different steel-HSLA65. [18, 24]The "M" profile is clearly visible for the longitudinal residual stresses. The magnitude of the longitudinal residual stresses are somewhat lower than those measured for MA956. It is important to note that the nominal yield strength of the HSLA65 is $450 \mathrm{MPa}$, compared with the 900 MPa yield strength of the base MA956 material and 530-530 MPa yield strength of the MA956 SZ material. While Barnes et al. do not report the yield strength of the SZ material after FSW, they do show Vickers hardness values that are larger in the SZ than those reported here. The difference between the two alloys is that HSLA65 forms martensite, bainite, and ferrite in the SZ after FSW, thus making the material harder, and likely stronger, than the base plate material. FSW applied to another ferritic stainless steel, 409M, yields very different results from MA956, albeit under quite different FSW conditions. Lakshminarayanan and Balasubramanian performed FSW at a 1000 RPM and $90 \mathrm{mmpm}$ to a $4 \mathrm{~mm}$ thick plate with a tapered tungsten tool. [19] The resulting welds were significantly overmatched with an increase in yield strength from $364 \mathrm{MPa}$ in the base material to 610 in the SZ. This increase in strength was attributed to refinement of the ferrite grain size and to the formation of grain boundary martensite. As a finalcomparison, FSW of austenitic stainless steel (304LSS) produced a longitudinal residual stress distribution that did not show a clear "M" profile and was instead quite similar to the residual stress profile observed from fusion welding. [14]The point here is that FSW conditions alone cannot predict the residual stress distribution after welding; the type of steel and its solid state phase transformations must be considered when predicting the level of residual stress after friction stir welding.

The large, tensile residual stresses measured in this study will likely reduce the fatigue strength of a friction stir welded plate. A simple estimate of the potential impact of the residual stresses may be made using the Goodman approach for fatigue strength at constant life (equation 1).[26] In this approach, a reduction in fatigue strength (amplitude stress $\left(\sigma_{\mathrm{a}}\right)$ for a fixed fatigue life), is related to the ratio of the mean stress $\left(\sigma_{\mathrm{m}}\right)$ to the ultimate tensile strength of the material, $\sigma_{\text {UTS }}$. The original fatigue strength with no mean (or residual) stress is given by $\sigma_{\mathrm{o}}$.

$$
\sigma_{a}=\sigma_{o}\left(1-\frac{\sigma_{m}}{\sigma_{U T S}}\right)
$$


While no fatigue data exists for MA956, there is some limited information on PM2000, a very similar, commercial alloy. Chao et al. have measured the room temperature fatigue behavior of PM2000 after heat treatment.[27] Here, we will use the $\sigma_{\mathrm{o}}$ value given by Chao for as-received PM2000 plate, $320 \mathrm{MPa}$ (for $\mathrm{N}_{\mathrm{f}}=10^{8}$ cycles). The UTS values are from the measurements on SZ material by Baker[12] and are given in Table 3. We will take the measured residual stress values to be the mean stress values. Using these values, we plot the predicted reduction in fatigue strength for MA956/PM2000 as a function of mean stress (Figure 12). The solid line shows the prediction using the larger UTS value from the MA956 base-plate material. The dashed line shows the prediction using the much-reduced UTS value from the SZ material under the 400/100 FSW condition. Fatigue cracking would be expected for amplitude stresses above these lines and not for amplitude stresses below the lines. The window shown on Figure 12 gives the range of tensile residual (mean) stress values measured for the 400/100 FSW condition. As a reminder, the larger values occurred near the TMAZ, while the SZ values were much lower. Even the lowest tensile residual stress values measured coulddecrease the fatigue strength to less than $250 \mathrm{MPa}$ (a 22\% reduction). The large difference between the solid and dashed curves shows the importance of accounting for the change in microstructure and mechanical properties between the plate material and the material in the welded region.It should be noted; however, that this simple model may be insufficient to capture the effects of the complex distribution of stresses in the friction stir welded microstructure. In addition to the tensile stress regions, there are also compressive stress regions that may slow fatigue crack growth locally. Future research should include actual fatigue testing of friction stir welded MA956 plate, or other ODS alloys or steels, to determine accuracy of these predictions.

A similar approach was taken by Lemmen et al for FSW of AA2024-T3.[28] In their work, the measured S-N fatigue strength for friction stir welded samples correlated directly with the magnitude of measured longitudinal residual stress. The lowest fatigue strengthscorresponded to the fatigue samples with the largest, tensile longitudinal residual stress. They used a modified Goodman model to compare with the experimental data and found reasonable agreement for moderate levels of mean/residual stress. 


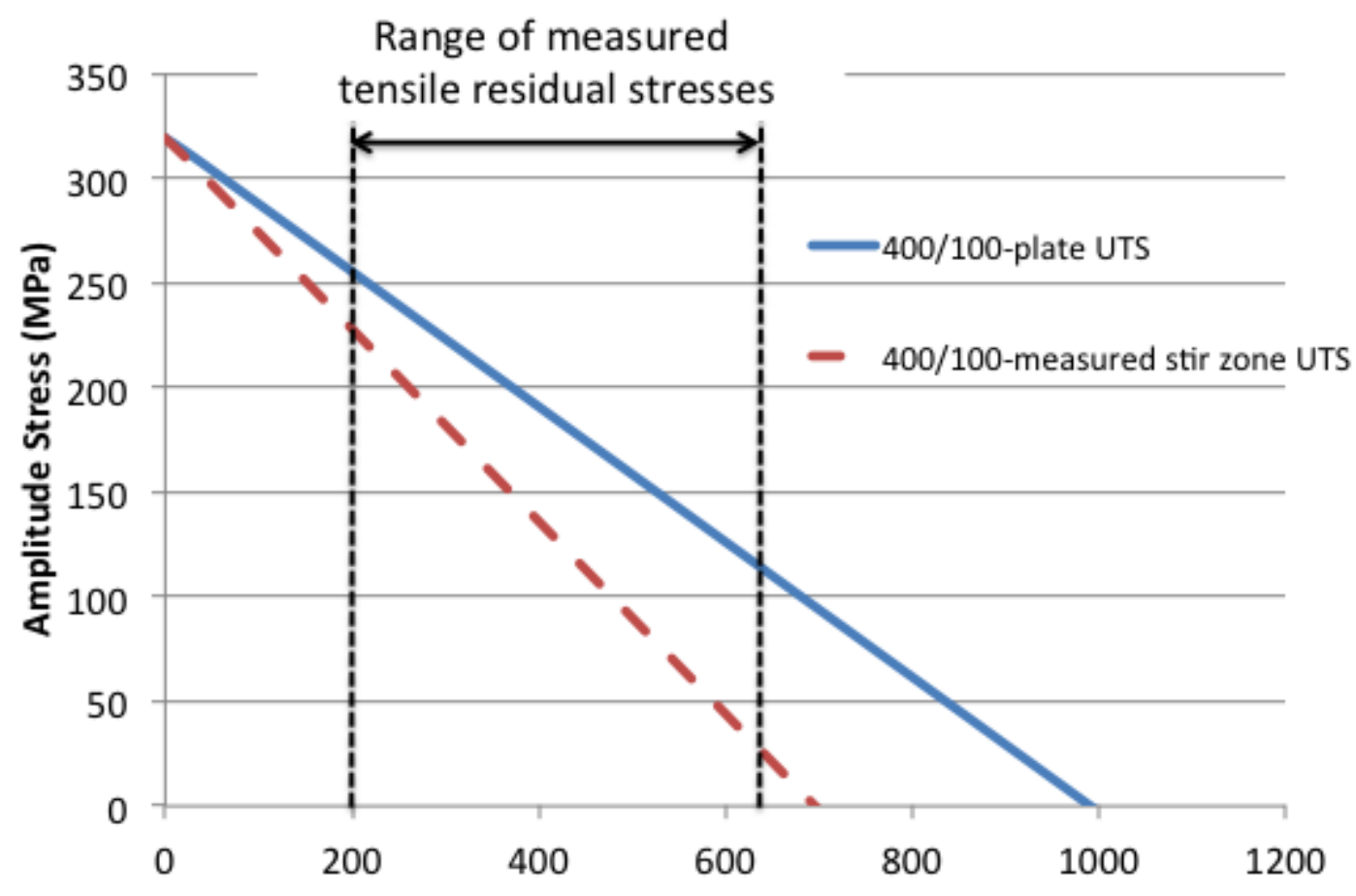

Figure 12. A Goodman plot $\left(\mathrm{N}_{\mathrm{f}}=10^{8}\right.$ cycles at $\left.\sigma_{0}=320 \mathrm{MPa}\right)$ for the friction stir weld of the 400/100 condition. The blue (solid) curve shows the predicted reduction in fatigue strength with increasing mean stress using the UTS of MA956 plate. The red (dashed) curved shows the predicted reduction in fatigue strength using the UTS measured from the SZ of the weld under the 400/100 FSW condition.

The use of both x-ray and neutron diffraction to measure the residual stresses is important from a fatigue crack nucleation and propagation standpoint. The diffraction volume for the chromium k-alpha x-rays is quite small with a depth of less than $60 \mu \mathrm{m}$ below the surface. The x-ray diffraction measurements cantherefore be assumed to represent the stress levels on the as-welded surface of the steel. The majority of fatigue cracks will nucleate at a free surface due to the formation of extrusions and intrusions promoted by persistent slip bands. The general concern with using only x-ray residual stress measurements is that the surface values are not indicative of the residual stress values in the bulk of the material. Neutron diffraction has the ability to sample cubic millimeters of material from within the macroscopic plate. The tensile residual stresses measured in the bulk would be important in controlling the growth of a fatigue crack 
nucleated at the surface. For the results in this study, the surface and bulk residual stress levels agree well.

\section{Conclusions.}

This article examines the use of x-ray and neutron diffraction for measuring the distribution of residual stresses following FSW of MA956 ODS steel. Three FSW conditions were examined with an increasing ratio of the rotational to traverse speeds. Both x-ray and neutron diffraction recorded large, tensile residual stresses along the longitudinal direction of the friction stir welds. The longitudinal residual stresses were much larger than the transverse or normal residual stresses, and the surface residual stresses on the root surface of the weld were somewhat larger than on the crown side.The magnitude of the residual stresses was inversely proportional to the ratio of the rotational to traverse speeds during welding. An increase in traverse rate increased the residual stress values measured.The x-ray and neutron diffraction data agreed well in the spatial distribution of stresses and the correlation of residual stress level with FSW parameters. The residual stresses measured were up to eighty percent of the plate value strength at the TMAZ and forty-fifty percent of the yield strength at the center of the SZ. The results of this paper suggest that the longitudinal residual stresses from FSW may reduce the fatigue strengthin welded ODS plate material.

\section{Acknowledgements:}

This work in part was performed under the auspices of the U.S. Department of Energy by Lawrence Livermore National Laboratory under Contract DE-AC52-07NA27344. The two plates measured in this study were provided by Lawrence Livermore National Laboratories. We are grateful for technical assistance from Dr. E.S.K. Menon at NPS.

Research conducted at ORNL's High Flux Isotope Reactor was sponsored by the Scientific User Facilities Division, Office of Basic Energy Sciences, US Department of Energy. 


\section{References:}

[1] M.G. McKimpson, D. Odonnell, JOM-Journal of the Minerals Metals \& Materials Society, 46 (1994) 49-51.

[2] R. Lindau, M. Klimenkov, U. Jaentsch, A. Moeslang, L. Commin, Journal of Nuclear Materials, 416 (2011) 22-29.

[3] H.J.K. Lemmen, K.J. Sudmeijer, I.M. Richardson, S. van der Zwaag, Journal of Materials Science, 42 (2007) 5286-5295.

[4] R.S. Mishra, Z.Y. Ma, Materials Science \& Engineering R-Reports, 50 (2005) 1-78.

[5] J.W. Qian, J.L. Li, F. Sun, J.T. Xiong, F.S. Zhang, X. Lin, Scripta Materialia, 68 (2013) 175-178.

[6] B.W. Baker, L.N. Brewer, E.S.K. Menon, T.R. McNelley, B. El-dasher, S. Torres, J.C. Farmer, M.W. Mahoney, S. Sanderson, Influence of Heat Input on Friction Stir Welding for the ODS Steel MA956, in: R.S. Mishra, M.W. Mahoney, S. Yutaka, Y. Hovanski, R. Verma (Eds.) Friction Stir Welding and Processing VII, Wiley, 2013. [7] C.L. Chen, P. Wang, G.J. Tatlock, Materials at High Temperatures, 26 (2009) 299303.

[8] D.T. Hoelzer, K.A. Unocic, M.A. Sokolov, Z. Feng, Journal of Nuclear Materials, 442 (2013) S529-S534.

[9] M.H. Mathon, V. Klosek, Y. de Carlan, L. Forest, Journal of Nuclear Materials, 386 (2009) 475-478.

[10] J. Wang, W. Yuan, R.S. Mishra, Journal of Nuclear Materials, 442 (2013) 1-6.

[11] J. Wang, W. Yuan, R.S. Mishra, I. Charit, Journal of Nuclear Materials, 432 (2013) 274-280.

[12] B.W. Baker, T.R. McNelley, L.N. Brewer, Materials Science and Engineering-A, 589 (2014) 217-227.

[13] N. Kumar, R.S. Mishra, J.A. Baumann, Residual Stresses in Friction Stir Welding, Butterworth-Heinemann, Oxford, UK, 2014.

[14] A.P. Reynolds, W. Tang, T. Gnaupel-Herold, H. Prask, Scripta Materialia, 48 (2003) 1289-1294.

[15] M. Peel, A. Steuwer, M. Preuss, P.J. Withers, Acta Materialia, 51 (2003) 47914801.

[16] C.M. Chen, R. Kovacevic, Proceedings of the Institution of Mechanical Engineers Part B-Journal of Engineering Manufacture, 220 (2006) 1359-1371.

[17] A. Bastier, M.H. Maitournam, F. Roger, K. Dang Van, Journal of Materials Processing Technology, 200 (2008) 25-37.

[18] A. Steuwer, S.J. Barnes, J. Altenkirch, R. Johnson, P.J. Withers, Metallurgical and Materials Transactions a-Physical Metallurgy and Materials Science, 43A (2012) 2356-2365.

[19] A.K. Lakshminarayanan, V. Balasubramanian, Materials Science and Engineering-A, 539 (2012) 143-153.

[20] I.C. Noyan, J.B. Cohen, Determination of Strain and Stress Fields by Diffraction Methods, Residual Stress: Measurement by Diffraction and Interpretation, SpringerVerlag, New York, 1987, pp. 117-162.

[21] M.T. Hutchings, P.J. Withers, T.M. Holden, T. Lorentzen, Practical Aspects of

Strain Measurement Using Neutron Diffraction, Introduction to the Characterization 
of Residual Stress by Neutron Diffraction, CRC Press, Boca Raton, FL, 2005, pp. 149202.

[22] H. Xu, C.R. Hubbard, K. An, Z. Feng, X.-L. Wang, J. Qu, Advanced Engineering Materials, 11 (2009) 650-653.

[23] B.W. Baker, E.S.K. Menon, T.R. McNelley, L.N. Brewer, B. El-dasher, J.C. Farmer, S. Torres, M.W. Mahoney, S. Sanderson, Metallurgical and Materials Transactions E, in press (2014).

[24] S.J. Barnes, A.R. Bhatti, A. Steuwer, R. Johnson, J. Altenkirch, P.J. Withers, Metallurgical and Materials Transactions A-Physical Metallurgy and Materials Science, 43A (2012) 2342-2355.

[25] L.Y. Wei, T.W. Nelson, Welding Journal, 90 (2011) 95S-101S.

[26] M.A. Meyers, K.K. Chawla, Fatigue, Mechanical Behavior of Materials,

Cambridge University Press, New York, NY, 2009, pp. 719-721.

[27] J. Chao, J.L. Gonzalez-Carrasco, C. Capdevila, Iron and Steel Institute of Japan International, 47 (2007) 1214-1220.

[28] H.J.K. Lemmen, R.C. Alderliesten, R. Benedictus, International Journal of Fatigue, 32 (2010) 1928-1936. 